\title{
Developing Double Walls System to Improve Building Energy Performances in Dry Tropical Climates
}

\author{
Etienne MALBILA (1) 1,3\#, Fati ZOMA²,3, David Y. K. TOGUYENI ${ }^{2,4}$, Chris-veenem \\ Methushael COMPAORE5 ${ }^{5}$, Dieudonné Joseph BATHIEBO ${ }^{1}$ \\ ${ }^{1}$ Laboratory of Thermal and Renewable Energies, University Joseph KI-ZERBO, Ouagadougou, \\ Burkina Faso. \\ ${ }^{2}$ Laboratory of Physics and Chemistry of Environment, University Joseph KI-ZERBO, \\ Ouagadougou, Burkina Faso. \\ 3University of Fada N'Gourma, Burkina Faso. \\ ${ }^{4}$ Polytechnic School of Ouagadougou, Burkina Faso. \\ ${ }^{5}$ High School of Public Works of Ouagadougou, Burkina Faso.
}

\#corresponding author

Type of Work: Peer Reviewed.

DOI: 10.21013/jas.v16.n3.p1

DOI URL: https://dx.doi.org/10.21013/jas.v16.n3.p1

\section{How to cite this paper:}

Malbila, E. et al. (2021). Developing Double Walls System to Improve Building Energy Performances in Dry Tropical Climates. IRA-International Journal of Applied Sciences (ISSN 24554499), 16(3), 39-52. DOI: https://dx.doi.org/10.21013/jas.v16.n3.p1

(C) IRA Academico Research.

(cc) BY-Nc This work is licensed under a Creative Commons Attribution-NonCommercial 4.0 International License subject to a proper citation to the publication source of the work.

Disclaimer: The scholarly papers as reviewed and published by IRA Academico Research are the views and opinions of their respective authors and are not the views or opinions of IRA Academico Research. IRA Academico Research disclaims any harm or loss caused due to the published content to any party.

IRA Academico Research is an institutional publisher member of Publishers International Linking Association Inc. (PILA-CrossRef), USA. IRA Academico Research is an institutional signatory to the Budapest Open Access Initiative. Hungary advocating the open access of scientific and scholarly knowledge. IRA Academico Research is a registered content provider under Open Access Initiative Protocol for Metadata Harvesting (OAl-PMH).

The journal is indexed \& included in WorldCat Discovery Service (USA), CrossRef Metadata Search (USA), WorldCat (USA), OCLC (USA), Open J-Gate (India), EZB (Germany) Scilit (Switzerland), Airiti (China), Bielefeld Academic Search Engine (BASE) of Bielefeld University, Germany, PKP Index of Simon Fraser University, Canada. 


\section{ABSTRACT}

This paper deals with building envelope thermal performance through a comparative study of the use of two types of construction materials, such as CEB and cement blocks, in order to introduce the use of double walls in sustainable buildings construction. The building envelope participates in providing thermal comfort to users and in the optimal management of building energy consumption. This study begins with a survey of public preferences for building materials used in Burkina Faso. The results indicate that $76 \%$ of the people surveyed opt for cement blocks over local materials. Concerning the thermal and specific energy performance, three variants of building envelope were studied: $C E B$ walls, cement blocks and the double-wall (CEB + Cement blocks). It appears that the $C E B$ walls are more efficient than the cement block walls. The introduction of double envelopes leads to the thermal resistance of $357.37 \mathrm{~m}^{2} . \mathrm{K} / \mathrm{W}$ and reduces the heat flow from $85.32 \%$ to $90.24 \%$ compared to the wall made with CEB and cement blocks. This approach, which consists in mixing construction materials for good thermal insulation, allows improving the envelope thermal performance and the overall building energy performance.

Keywords: Numerical study, Building energy performances, Compressed Earth Block, Conventional Cementitious material, double walls envelope.

\section{Introduction}

The country development level is linked to the infrastructures (monuments, bridges, buildings, etc.) quantities and qualities and their ability to meet the population needs. In this context, the rapid growth and strong expansion of infrastructure has an environmental impact and is accompanied by increasing energy needs. The construction sector offers opportunities for action to address this energy and environmental pressure, provided that certain options are adopted in the design, construction and operation of infrastructure in general and housing in particular. Considering that one measure for more cost-effective and rational use of energy resources in individual residential buildings is the application of passive solar systems with a sunspace (Vukadinović, Radosavljević, Petrović, \& Đorđević, 2019).

The building sector has great potential to improve energy-efficient and reduce the ecologic impact (Bahrar, 2018).To contribute to this, we are interested in the thermal comfort of the building which is related to several aspects, including construction materials. The mechanical, physical and thermal performances differ from constructions materials and therefore influence the building design options. Indeed, a good building envelope design contributes to reducing effectively building energy consumption and the associated $\mathrm{CO} 2$ emissions (Bahrar, 2018)and the behaviour of the envelope is highly influenced by the materials used. Therefore, the management of building envelope becomes essential to carry efficient construction (GOSSARD, BONTE, LARTIGUE, \& THELLIER, 2001) This study aims to identify appropriate material and propose an alternative approach of mixed material construction (local and modern materials) for more performance of building envelope. Building thermal comfort became a very important issue for development. Therefore, building techniques that reduce environmental impacts by minimizing industrial processes and using locally available materials, such as earth, are receiving a new impetus. (Ávila, Puertas, \& Gallego, 2020).Indeed, nowadays we are witnessing a constructions standardization that consists in building in cement blocks with a corrugated iron roof and a non-ventilated attic and not taking into account the climate. While the former constructions taking into account the climate (use of local materials) associating a local adapted spatial organization. However, the choice of building materials is also essential to have a building with low energy consumption contributing to sustainable development.

This study's aim is to optimize the building external wall and make it more efficient from an energy and thermal comfort point of view. In the energy efficiency field, there are several approaches, each with its strategy that targets a particular aspect (Boursas \& Mehri, 2012). The aim is to exploit two appropriate materials and propose a double-wall design integrating the two materials in order to reduce building heats gains.

\section{Material \& Method}

\subsection{Material Choice Survey}


Construction materials are an important link in the building sector. Their availability is crucial to the achievement of development goals and the buildings constructed cost. (Khawla, Dada, \& Bassoud, 2016).To contribute to the promotion of appropriate materials, a survey was conducted in this study. Thus, the public opinions on their constructions projects were collected with the main question: Which material would you like to use for building walls construction; cement blocks, earth bricks, or cut stone blocks?

\section{Sampling to the information collection}

The information collection was operated with survey forms filled out by a sample of 110110 individuals (99 men and 11 women), engaged in different activities such as student, trader, the government employed, agricultural agent, artisan, and accountant. The data collected concerned the following elements: gender, age, occupation, material choice, and choice justification. They are more quantitative and will be entered and processed with Excel software.

\section{Survey conduct and period}

This survey was conducted from August $1^{\text {st }}$ to 10, 2017inthe three districts in Bobo-Dioulasso: Yeguere, Accar Ville and district 22. The administration of the form was done from 8:00 am to 12:00 am and 2:00 pm to 6:00 pm each day during the period of the survey.

\subsection{Energy Performance Optimization Method}

The study framework is described in Figure 1. The originality of this work is the introduction to housing double wall system construction in the dry tropical climate. The research work has shown that the envelope influences building overall performance and the wall assembly performance depends on each wall components specific performance (Lacasse, 2003). To do this, it will be essential to study separately each construction material thermal performance and then combine them for a building envelope wall alternative option.

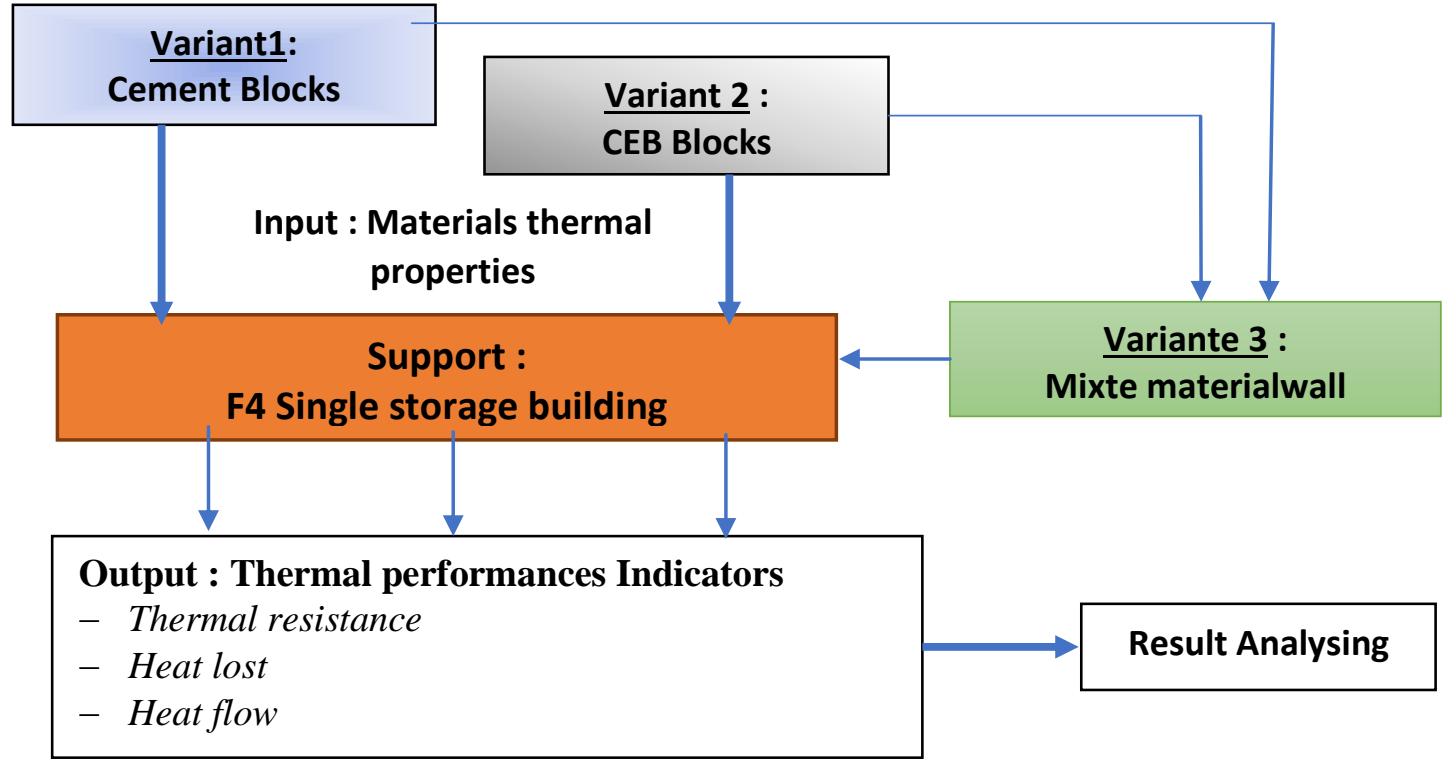

Figure 1: Study framework

\subsubsection{Building Choice and Description}

The building sector is considered a major energy consumer (almost half of the global consumption) and is also responsible for $25 \%$ of greenhouse gas emissions. This consumption reduction is the builder's mains preoccupation who inscribe their reflection within the framework of sustainable development or of the high environmental quality (Sotehi, 2010) The the study will focus on thermal performances comparison of two types of constructions materials, the CEB and cement blocks in an F4 single storage building (Figure 2). 


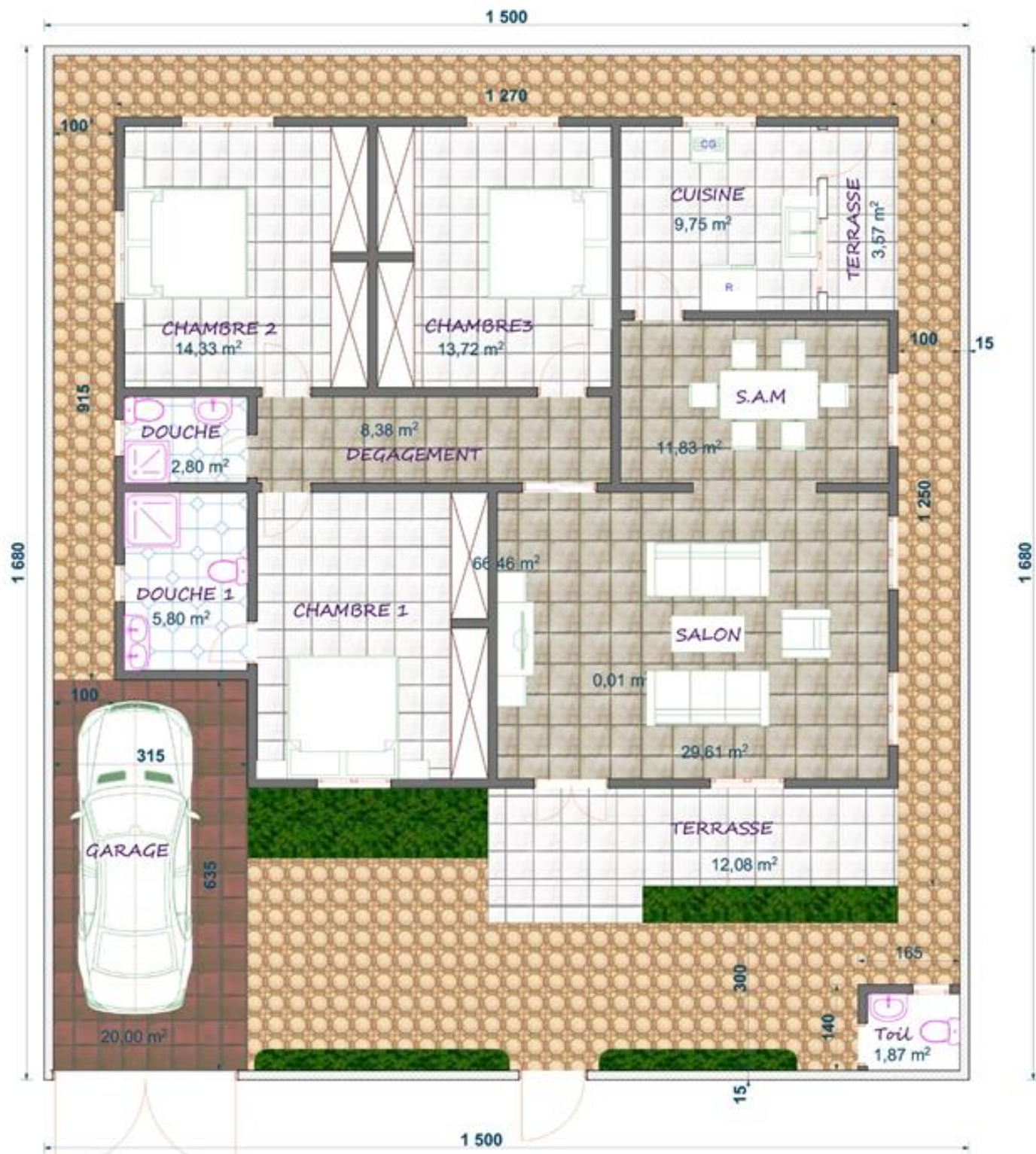

Figure 2: Plot and building layout

From architecture design, the building consists of a single bloc composed built on a plot of $240 \mathrm{~m}^{2}$ and a living area of $125.39 \mathrm{~m}^{2}$ divided into 9 rooms.

\subsubsection{Envelope Components and Material Description}

The building envelope components and constructions materials used are described in tables 1 and 2 .

Table 1: Envelope components and material description

\begin{tabular}{llll}
$\mathbf{N}^{\circ}$ & Building part & Variant 1: Conventional material & Variant 2: Local materials \\
\hline $\mathbf{1}$ & Roof & Galvanized sheet $35 / 100$ & Vibrated mortar tile \\
$\mathbf{2}$ & False ceiling & Plywood thick $5 \mathrm{~mm}$ & Plywood thick $5 \mathrm{~mm}$. \\
$\mathbf{3}$ & Wall & Cement blocks $15 \times 20 \times 40 \mathrm{~cm}$. & CEB thick $20 \mathrm{~cm}$ \\
$\mathbf{4}$ & $\begin{array}{l}\text { Internal and external } \\
\text { coating }\end{array}$ & Cement mortar thick $2.5 \mathrm{~cm}$ & Lime plaster thick $5 \mathrm{~cm}$ \\
$\mathbf{5}$ & Windows & aluminium single glazing thick6mm & aluminium single glazing thick \\
\hline
\end{tabular}


Below Table 2 presents materials thermal and physicals properties used in this study. The control of these properties allows the precise evaluation of construction thermal comfort and energy performances.

Table 2: Constructions materials properties

\begin{tabular}{lcccc}
\hline \multicolumn{1}{c}{ Material } & $\boldsymbol{\lambda}(\mathbf{W} / \mathbf{m . k})$ & $\boldsymbol{\rho}\left(\mathbf{K g} / \mathbf{m}^{\mathbf{3}}\right)$ & $\boldsymbol{C}_{\boldsymbol{p}}(\mathbf{k J} / \mathbf{k g} \cdot \mathbf{K})$ & $\mathbf{E p .}(\mathbf{c m})$ \\
\hline Metal sheet roof & 70 & 7800 & 0.800 & 0.3 \\
Plywood & 0.14 & 600 & 2.72 & 0.5 \\
Cement blocks & 0.95 & 1250 & 0.88 & 15 \\
Cement mortar & 1,15 & 2200 & 1.05 & 5 \\
Vibrated mortar tile & 1,15 & 1800 & 0.900 & 1.2 \\
CEB & 1 & 1700 & 0.900 & 20 \\
Lateritic earth plaster & 0.900 & 1600 & 0.900 & 5 \\
Lime plaster & 0.87 & 600 & 0.900 & 1 \\
Glazing & 1 & 2500 & 750 & 0.6 \\
\hline
\end{tabular}

\subsubsection{Thermal Performance Calculation Principle}

For building envelope thermal performance study, several physical parameters are to be considered. It is important to define suitable descriptive indicators. Indeed, criteria allowing to evaluate the energy performance are defined, like Building annual energy performance and occupants thermal comfort (GOSSARD, BONTE, LARTIGUE, \& THELLIER, 2001) For this purpose, these parameters and quantities are described in the following paragraphs.

\section{1) The thermal resistance of each material component $\left(R_{T}\right)$}

The thermal resistance (RT) characterizes the material ability to slow down heat transfer by conduction. It is calculated with the following equation:

$$
R_{T}=\frac{e}{\lambda}
$$

With:

- $\boldsymbol{R}_{T}$, in $m^{2} . K / W$ Thermal resistance ;

- $\quad \boldsymbol{e}$, thickness in $m$

- $\quad \lambda$, thermal conductivity in $W /(m \cdot K)$.

\section{2) Wall global thermal resistance $\left(R_{t p}\right)$}

It characterizes the sum of heat transfer by conduction within the material and surface heat exchange by convection and radiation.

$$
\mathbf{R}_{t \boldsymbol{P}}=\mathbf{R s i}+\mathbf{R s e}+\boldsymbol{\Sigma}(\mathbf{e} / \lambda), \text { in } \mathrm{m}^{2} . \mathrm{K} / \mathrm{W}
$$

\section{3) Heat lost $\left(U_{p}\right)$}

The thermal transmittance (UP) reflects the heat quantity escaping through a wall. It is the inverse of the overall thermal resistance. It is expressed in $\mathrm{W} /\left(\mathrm{m}^{2} . \mathrm{K}\right)$ or in $\mathrm{W} /\left(\mathrm{m}^{2} .{ }^{\circ} \mathrm{c}\right)$.

$$
\mathbf{U p}=\frac{1}{R p}
$$

With :

- Up, the heat lost;

- $R_{P}$, the sum of wall different layers thermal resistances, in $m^{2} . K / W$.

\section{4) Heat flow $(\varphi)$}


The Heat flow $(\varphi)$ is the quantity of energy or heat passing through $1 \mathrm{~m}^{2}$ of the wall during one second when there is a temperature gap between its two sides. It is expressed in $\mathrm{W} / \mathrm{m}^{2}$.

$$
\varphi=\lambda \times \frac{\Delta \mathbf{T}}{\mathbf{e}}
$$

With :

- $\lambda$, thermal conductivity in $W /(m . K)$. ;

- $\Delta T$, temperature gap in ${ }^{\circ} \mathrm{K}$;

- $\quad$, thickness in $m$.

\section{5) Glazing thermal transmittance: Ug ou K}

The thermal transmittance coefficient $\mathbf{U g}$ or $\mathbf{K}$ characterizes the heat quantities of heat escaping from glazing ( $\mathrm{g}$ for glass/glazing) of $1 \mathrm{~m}^{2}$ for a differential of 1 degree. It is calculated according to the thermal resistances following the equation 5 :

$$
U_{g}=\frac{1}{\sum \frac{d_{j}}{\lambda_{j}}+\sum R_{s, k}+R_{s e}+R_{s i}}
$$

With:

- $\quad d_{j}$ : glazing or material thickness $j$ (excepted air or gas), in $m$;

- $\quad \lambda_{j}$ : material layer or glass thermal conductivity, in $W /(m . K)$;

- $\quad R_{s, k}$ : air gap or gas thermal resistance, in $m^{2} . K / W$ :

- $R_{s i}$ and $R_{s e}$ : surface thermal resistance in $m^{2} . K / W$.

All calculations were performed using Excel software and the calculation principle is built in three steps:

- The material's performance;

- The building walls envelope performance by part of the structure;

- The building global performance.

\subsubsection{Approach to Mix Local and Modern Material for Double Wall}

The construction processes have evolved over the years as well as the materials used (Borderon, Cantin, \& Virgone, 2008).To reduce buildings energy consumption, passive solutions have been developed by strongly increasing exterior wall insulation. One of the ways to improve the buildings energy efficiency is to design multifunctional facades that can capture locally available energy: this is the hybrid envelopes principle, capable of insulating and protecting, but also capturing, storing and transporting energy (Joussellin, Faure, Johannes, Pierson, \& Quénard, 2008).To do this, the present study envisages finding with the same architectural plan a compromise between the two cases of materials for a double-wall option to offer more building thermal performance. The double-wall protects from rainwater infiltration thus improving the construction durability. The double wall water tightness is in fact ensured by a double barrier: the facing masonry and the air space between it and the thermal insulation (Règles de l'Art Grenelle Environnement 2012, 2014).

In this alternative approach, the envelope materials are described in Figures 3 and 4:

- Roof: reinforced concrete slab thick $20 \mathrm{~cm}$ topped and protected by a metal sheet roofing;

- Double facade walls (thickness $40 \mathrm{~cm}$ ) composed of $20 \mathrm{~cm}$ CEB and cement blocks of $15 \mathrm{~cm}$ separated by an air gap of $5 \mathrm{~cm}$;

- Interior walls in cement blocks of $10 \mathrm{~cm}$ (exclusively for the partitioning);

- Windows: double glazing thickness $2 * 6 \mathrm{~mm}$ and separated by an air gap of $1 \mathrm{~cm}$. 


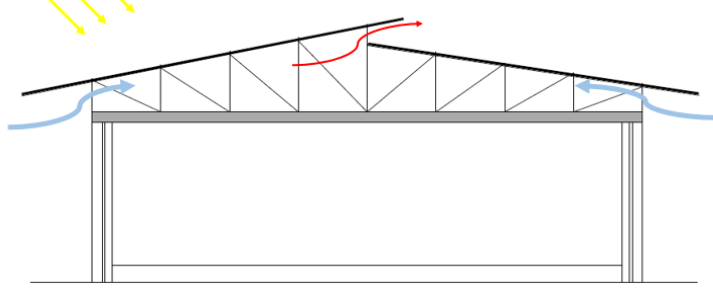

Figure 3: Roof and airflow principle (Reinforced concrete floor+Sheet metal roof)

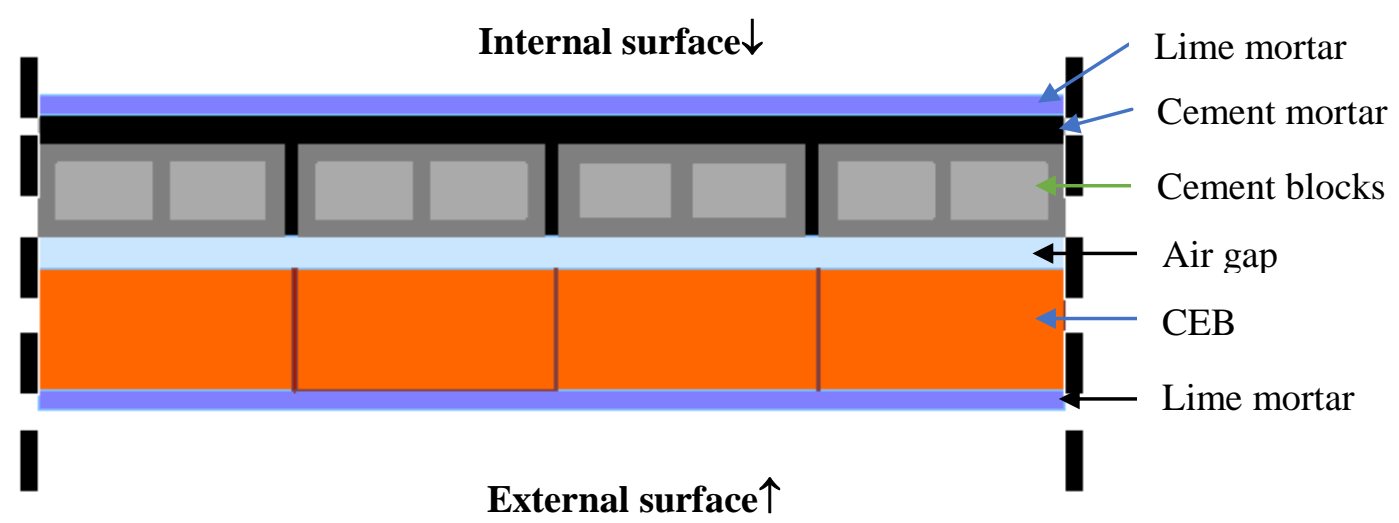

Figure 4: Description of double-wall components

\section{Results}

\subsection{Construction Material Choice}

The construction material influence in building overall performance is a reality. However, the construction material choice is a function of many factors depending on the designer and the promoter. In building material promotion, the opinion of the recipient public is not always taken into account; whereas the local population choices and preferences in terms of building materials would be an asset in the promotion of appropriate materials. Now, the new approach recommends that the building operational phase be taken into account from the design stage. The average age of the individuals surveyed is 36.53 years and the preferences of the materials are given in Figure 5.

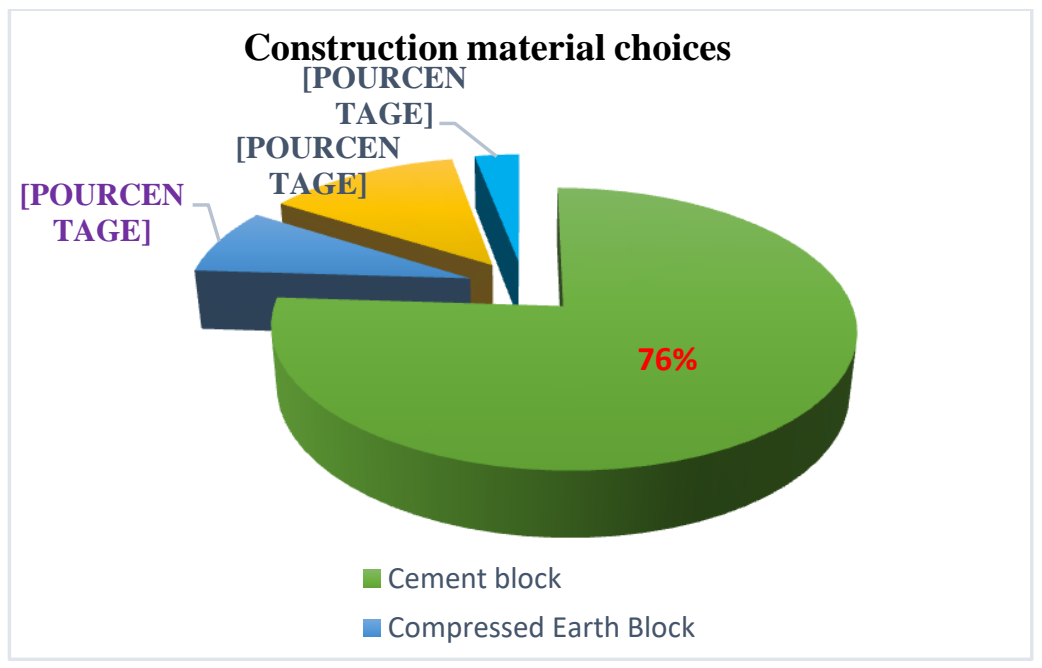

Figure 5: Construction material choice from survey 
In this graph, it appears that $76 \%$ of the people surveyed opt for cement blocks. The reasons given are mainly:

- Durability and quality;

- The availability of cement and the speed in construction;

- Mastered technology and an abundance of qualified technicians;

- The modernity;

- The fear of building with another material than cement block;

- A guarantee that the house-made with cement blocks will not be maintained.

The percentage of people who opted for Cut Laterite Blocks (CLB) and Compressed Earth Bricks (CEB) are respectively $13 \%$ and $8 \%$. The reasons given are the same and concern the economy in the construction, the quality, the aesthetics, the thermal comfort and the adaptation to the climate. However, $3 \%$ refer to designer advice.

\subsection{Material Thermal Performance}

Table 3 below shows modern and local building materials thermal performance in the building envelope different components studied. These results are given per unit area $\left(\mathrm{m}^{2}\right)$ of each component.

Table 3: Synthesis of Thermal performances of construction materials used

\begin{tabular}{lccc}
\hline \multicolumn{1}{c}{ Material } & RT $\left(\mathbf{m}^{2} \cdot \mathbf{K} / \mathbf{W}\right)$ & Up W/ $\left(\mathbf{m}^{2} . \mathbf{K}\right)$ & $(\boldsymbol{\varphi}) \mathbf{W} / \mathbf{m}^{2}$ \\
\hline Metal sheet & 0.000043 & 23333.33 & 350000 \\
Plywood & 0.0357 & 28 & 420 \\
Cement blocks & 0.158 & 6.33 & 95 \\
Cement mortar & 0.0435 & 23 & 345 \\
TMV & 0.0104 & 95.833 & 1437.5 \\
CEB & 0.20 & 5 & 75 \\
Lime plaster & 0.0574 & 17.4 & 261 \\
Glazing & 0.006 & 166.67 & 2500 \\
\hline
\end{tabular}

\subsection{Building Envelope Component Thermal Performance}

The building envelope component thermal performances are presented in Tables 4 and 5 . These results take into account the layers numbers and the building of each part components.

Table 4: Summary of building envelope components thermal performances_Variant 1

\begin{tabular}{lccccc}
\hline Material & $\begin{array}{c}\mathbf{R T} \\
\left(\mathbf{m}^{2} . \mathbf{K} / \mathbf{W}\right)\end{array}$ & $\mathbf{S}\left(\mathbf{m}^{2}\right)$ & $\begin{array}{c}\mathbf{R T} \text { total } \\
(. \mathbf{K} / \mathbf{W})\end{array}$ & $\begin{array}{c}\text { Up W/ } \\
\left(\mathbf{m}^{2} . \mathbf{K}\right)\end{array}$ & $\begin{array}{c}(\boldsymbol{\varphi}) \\
(\mathbf{k W})\end{array}$ \\
\hline Metal sheet roof & 0.000042 & 134.74 & 0.00576 & 173.40 & 47159 \\
False ceiling in plywood & 0.0357 & 108.75 & 3.88 & 0.257 & 45.675 \\
Coat internal Cement blocks wall & 0.245 & 105.965 & 25.95 & 0.039 & 6.491 \\
Coat external Cement blocks wall & 0.245 & 145.273 & 35.57 & 0.028 & 8.899 \\
Glazed metal windows and doors & 0.006 & 15.36 & 0.092 & 166.67 & 38.400 \\
\hline
\end{tabular}


IRA-International Journal of Applied Sciences

Table 5: Summary of building envelope components thermal performances Variant 2

\begin{tabular}{|c|c|c|c|c|c|}
\hline Material & $\begin{array}{c}\text { RT } \\
\left(\mathbf{m}^{2} . \mathrm{K} / \mathrm{W}\right)\end{array}$ & $\begin{array}{l}\text { Surface area } \\
\qquad\left(\mathbf{m}^{2}\right)\end{array}$ & $\begin{array}{l}\mathbf{R T} \text { total } \\
\left(\mathbf{m}^{2} . \mathbf{K} / \mathbf{W}\right)\end{array}$ & $\begin{array}{l}\text { Up W/ } \\
\left(\mathbf{m}^{2} \cdot \mathbf{K}\right)\end{array}$ & $\boldsymbol{\varphi}(\mathrm{en} \mathrm{k} \mathbf{W})$ \\
\hline TMV roof & 0.000042 & 134.74 & 1.40 & 0.711 & 193.689 \\
\hline False ceiling in plywood & 0.0357 & 108.75 & 3.88 & 0.257 & 45.675 \\
\hline Internal wall in CEB & 0.315 & 105.965 & 33.37 & 0.029 & 4.312 \\
\hline External wall in CEB & 0.315 & 145.273 & 45.75 & 0.021 & 5.912 \\
\hline Glazed metal windows and doors & 0.006 & 15.36 & 0.092 & 10.85 & 38.400 \\
\hline
\end{tabular}

Table 6 presents the results of the building envelope thermals performances comparison

Table 6: Comparison of building envelope materials thermals performances

\begin{tabular}{|c|c|c|c|c|}
\hline \multicolumn{2}{|c|}{ Envelope and material } & \multirow{2}{*}{$\begin{array}{c}\text { RT total }\left(\mathbf{m}^{\mathbf{2}} \mathbf{. K} / \mathbf{W}\right) \\
0.00576\end{array}$} & \multirow{2}{*}{$\frac{\mathbf{U p ~ W} /\left(\mathbf{m}^{2} \cdot \mathbf{K}\right)}{173.40}$} & \multirow{2}{*}{$\begin{array}{r}\varphi(\mathbf{k W}) \\
47159\end{array}$} \\
\hline & Metal sheet & & & \\
\hline 15001 & TMV & 1.40 & 0.711 & 193.689 \\
\hline \multirow{2}{*}{ Internal wall } & Cement blocks & 25.95 & 0.039 & 6.492 \\
\hline & CEB & 33.37 & 0.029 & 4.312 \\
\hline \multirow{2}{*}{ External wall } & Cement blocks & 35.57 & 0.028 & 8.900 \\
\hline & CEB & 45.75 & 0.021 & 5.912 \\
\hline
\end{tabular}

Metal roofing logically has a very high heat flux compared to vibrated mortar tile (TMV), given the basic components. The ratio between the two flux quantities is about $1 / 200$. Its thermal resistance is also low compared to the TMV. Therefore, the tile offers more thermal comfort inside the building compared to sheet metal.

$>$ Cement block walls $(\varphi=6.492 \mathrm{~kW}$ and $8.900 \mathrm{~kW})$ have higher heat flow and heat loss compared to CEB ( $\varphi$ $=4.312 \mathrm{~kW}$ and $5.912 \mathrm{~kW}$ ) with an average difference of $2.179 \mathrm{~kW}$ to $2.987 \mathrm{~kW}$. The heat loss coefficients are all above the limits prescribed by RT 2005 concerning vertical opaque walls in new construction: $\mathrm{U}=$ $0.45 \mathrm{~W} /\left(\mathrm{m}^{2} . \mathrm{K}\right)$. All the values of thermal losses are homogeneous. The thermal loss of the cement block wall is lower than that of the CEB wall for both the partitions and the facades. The cement blocks retain less heat than the CEB. Thus the CEB has a higher thermal performance than the cement blocks (figure 6).

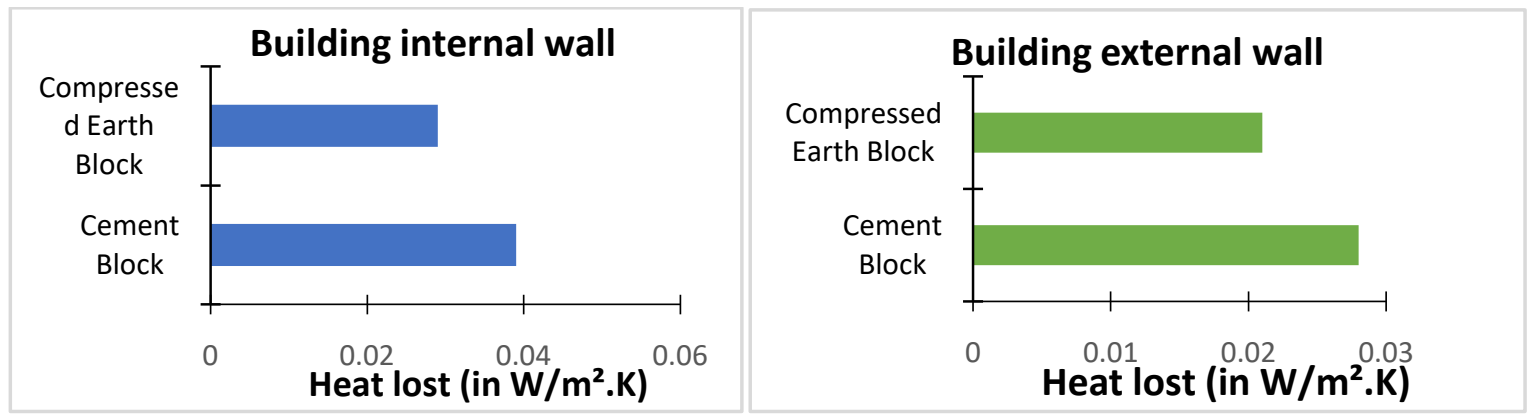

Figure 6: Heat lost coefficient $U\left(W /\left(m^{2} . K\right)\right)$ calculated for each type of wall

\subsection{Building Global Thermal Performance}

Table 7 below compares the total amount of energy (heat flow) entering the building through the envelopes (roof and walls) according to the construction materials used. 
IRA-International Journal of Applied Sciences

Table 7: Comparison of overall building performance by construction material used

\begin{tabular}{lccc}
\hline Building & $\varphi(\mathbf{k W})$ of wall & $\boldsymbol{\varphi}(\mathbf{k W})$ of roof & $\varphi_{\boldsymbol{T}}(\mathbf{k W})$ \\
\hline \hline Building in modern material & 8.90 & 47159 & 47167.90 \\
Building in local material & 5.912 & 193.70 & 199.600 \\
\hline \hline
\end{tabular}

In Table 7 , it can be seen that the total amount of heat $\left(\boldsymbol{\varphi}_{T}\right)$ entering the modern material building is higher than that of local material building. Thus, from the thermal point of view, the building with local materials performs better than the building with modern materials. The local materials used in the basic building envelope structures allow the total heat flow to be reduced by $99.58 \%$.

\subsection{Alternative Approach Proposal}

In view of the above results, an intermediate approach is envisaged by the study of double walls in mixed materials Cement blocks+CEB separated by an air gap. Table 8 presents the global results of thermal resistances, thermal losses and heat flow.

Table 8: Alternative approach envelope thermal performance

\begin{tabular}{lccccc}
\hline Material & $\begin{array}{c}\mathbf{R T} \\
\left(\mathbf{m}^{\mathbf{2}} \cdot \mathbf{K} / \mathbf{W}\right)\end{array}$ & $\begin{array}{c}\text { Surface area } \\
\left(\mathbf{m}^{\mathbf{2}}\right)\end{array}$ & $\begin{array}{c}\text { Global RT } \\
\left(\mathbf{m}^{\mathbf{2}} \cdot \mathbf{K} / \mathbf{W}\right)\end{array}$ & $\begin{array}{c}\mathbf{U p} \\
\mathbf{W} /\left(\mathbf{m}^{\mathbf{2}} \mathbf{. K}\right)\end{array}$ & $\begin{array}{c}\boldsymbol{\varphi} \\
(\mathbf{e n ~} \mathbf{k W})\end{array}$ \\
\hline Slab in concret & 0.098 & 134.74 & 13.20 & 0.076 & 20.615 \\
Internal walls & 0.25 & 105.965 & 26.49 & 0.038 & 6.358 \\
External walls & 2.46 & 145.273 & 357.37 & 0.0028 & 0.868 \\
Glazing & 0.412 & 15.36 & 6.427 & 0.156 & 0.568 \\
\hline
\end{tabular}

\subsection{Results Comparison}

The result comparison is made between the three envelope variants (double-wall, CEB, cement blocks) based on heat loss, heat flow and thermal resistance criteria. The results are summarized in below table 9 .

Table 9:Thermophysicals characteristics of the different envelope

\begin{tabular}{llccc}
\hline \multirow{2}{*}{ Envelope and Materials } & $\begin{array}{c}\text { Global RT } \\
\left(\mathbf{m}^{\mathbf{2}} \mathbf{. K} / \mathbf{W}\right)\end{array}$ & $\begin{array}{c}\text { Up in } \\
\mathbf{W} /\left(\mathbf{m}^{\mathbf{2} . \mathbf{K})}\right.\end{array}$ & $\boldsymbol{\varphi}(\mathbf{i n} \mathbf{k W})$ \\
\hline \multirow{3}{*}{ Exernal wall } & Cement block & 25.95 & 0.028 & 8.90 \\
& CEB & 45.75 & 0.019 & 5.912 \\
\multirow{2}{*}{ Glazing } & Double Wall & 357.37 & 0.0028 & 0.868 \\
& Simple Glazing & 0.092 & 10.85 & 38.400 \\
\hline
\end{tabular}

\section{Results Discussion}

\subsection{Main Results}

\subsubsection{Construction Materials Choice}

The individuals surveyed choice and/or preference is mostly for cement blocks, which are a conventional material known as "modern". At this survey outcome, the interpretation that can be made is on two levels:

- The local materials dropping in favour of modern materials; 
- The lack of consideration of certain factors related to materials such as the environmental impact and energy consumption impact in construction.

Building with cement-based materials has become a priority for many people in Burkina Faso. Indeed, according to INSD inventory in 2005,30\% to $60 \%$ of constructions are made with cement blocks in most developed regions in Burkina Faso (Institut National de la Statistique et de la Démographie (INSD), 2005). However, this material is not specifically adapted to dry tropical or Sahelian climates and is not accessible, unlike local materials. The evaluation of air-conditioning loads to ensure thermal comfort in these habitats shows that they are higher respectively in the cement blocks, BLT, CEB, adobe constructions. We, therefore, consider that local building materials represent a good alternative for the search for buildings energy efficiency (Compaore, Ouedraogo, Guengane, Malbila, \& Bathiebo, 2017) There are several reasons for this preference for modern material such as:

- The ignorance of local materials ecological qualities;

- The bias is against local materials and the modernism request;

- The lack of qualified manpower in local material technology ;

- The consideration of cement-based material as modern, more resistant and durable material.

\subsubsection{Building and Materials Specifics and Global Thermal Performances}

Inefficient building design, in addition, to propose less energy-consuming equipment, it is essential to control the envelope thermal exchanges (Faure, 2007) From obtained result analysis and comparison made, the following aspect appears:

- The metal sheet has a very high heat flux, compared to the tile with a total heat flux of $47159 \mathrm{~kW}$ while the Vibrated Mortar Tile (TMV) has a heat flux of $199.600 \mathrm{~kW}$. The metal sheet is heat conductive due to its thermal conductivity of $70 \mathrm{~W} /(\mathrm{m}$. K). Due to its very low thickness, it cannot oppose the temperature variations inside the building.

- Cement blocks are less efficient than CEB. In fact, cement blocks have a total heat flux of $8.90 \mathrm{~kW}$, while the CEB have a total heat flux of $5.912 \mathrm{~kW}$. Because of its thickness $(15 \mathrm{~cm})$ and its thermal conductivity $(0.95$ $\mathrm{W} /(\mathrm{m} . \mathrm{K}))$, cement blocks alone cannot offer thermal comfort, it could be efficient if their thickness was increased.

- CEB and TMV offer more thermal and energetic performances than metal sheet and cement blocks. They are therefore appropriate for dry tropical or Sahelian climates. The earth itself does not insulate but given its properties, it is better adapted to offer to build thermal comfort in dry tropical climates. The earth becomes a very good insulator if it is mixed with plant and animal debris (straw, cow dung, rice and fonio straw...);

- The envelope thickness plays a key role in building thermal insulation. The thermal resistance is 45.75 $\mathrm{m}^{2} . \mathrm{K} / \mathrm{W}$ for the CEB $(\mathrm{ep} . .=20 \mathrm{~cm})$ and $25.95 \mathrm{~m}^{2} . \mathrm{K} / \mathrm{W}$ for the cement block $(\mathrm{ep} .=15 \mathrm{~cm})$. The more it is large, the more it opposes to the heat transfer and variations, and inversely.

\subsubsection{Envelope Mixed System Development}

The design of envelopes that can improve energy gains while limiting losses must contribute to reducing energy needs without affecting indoor comfort. The envelope then becomes a real heat exchanger that can be managed and adapted to the interior and exterior environments (Faure, 2007). Thus, it is possible to act on the building materials and the design. In the present study, the following aspects appear:

- The double-wall (CEB + Air Blade + cement blocks) has a lower heat loss and heat flow than cement blocks and CEB walls. With this option, the intrinsic qualities of both building materials are exploited in the same home;

- The mixed system building envelope options have respectively higher thermal performances than those in local materials and modern materials;

- Specifically, at the roof level, the slab option has a much lower heat loss and heat flow than the TMV and sheet metal options; 
At these investigations completion, it is noted that this building mixed envelope approach presents a more attractive overall performance than buildings constructed with both local and modern material options.

\subsection{Strengths and Limits}

The results obtained in this study make it possible to appreciate the performance of the materials for an optimal choice; however, this study remains theoretical and does not take into account the occupancy and the equipment installed. Moreover, it does not integrate the dynamic variation of the site environmental conditions. A tendency, not new, but which seems to be asserting itself with more dynamism, would be to reconsider the calculation of building thermal loads by considering it in the variable regime and not in permanent as it is usually done (Huet, Castel, Amoros, \& Laquerbe, 1979).

\subsection{Implication on Practice and Research}

This study has highlighted the quality of local building materials compared to modern materials in the search for buildings thermal performance. The introduction of the mixed wall (local material/modern material) as an approach in the construction of walls opens perspectives in the improvement of the energy performance of the building envelopes. Even if its realization is more expensive because it requires more materials and a highly qualified workforce. However, it is important to consider:

- an experimental study by instrumentation of a double wall of an existing building;

- to model the single and double walls specific thermal behaviour;

- Integrate the dynamic variation of climatic conditions in the double-wall building energy characterization.

\section{Conclusion}

Through the construction material survey, many people consider modern materials to be the ideal building materials in the local context. Local materials are rejected and considered to be the materials of the poor. However, modern materials are expensive and unsuitable for the dry tropical climate. Also, the implementation of local materials is delicate and requires more mastery than modern materials. On the different cases of facade walls studied, the double-wall has a heat flux of $0.868 \mathrm{~kW}$ while cement blocks and CEB have respectively 8.90 $\mathrm{kW}$ and $5.912 \mathrm{~kW}$. Its thermal resistance of $357.37 \mathrm{~m}^{2} . \mathrm{K} / \mathrm{W}$ is higher than that of cement blocks $\left(25.95 \mathrm{~m}^{2} . \mathrm{K} / \mathrm{W}\right)$ and CEB $\left(45.75 \mathrm{~m}^{2} . \mathrm{K} / \mathrm{W}\right)$. This approach is much better and offers more thermal and energetic performance. Even if its realization is more expensive, because it requires more materials and a highly qualified workforce, it will allow the owner to make energy savings in the long term. The thermal performance achieved by the envelopes contributes to reducing the buildings energy needs, provided that the building materials option is adapted to the climatic environment. Thus, building materials that are available and used judiciously can provide adequate thermal and building overall performance.

\section{References}

[1] A. Vukadinović, J. Radosavljević, A. Petrović et N. Đorđević, Effects of the geometry of residential buildings with a sunspace on their energy performance, FACTA UNIVERSITATIS Series: Architecture and Civil Engineering, vol. 17(1), pp. 105-118, 2019.

[2] M. Bahrar, Contribution to the development and analysis of a multifunctional building envelope in the context of the habitat comfort optimization, Lyon, 2018.

[3] D. GOSSARD, M. BONTE, B. LARTIGUE et F. THELLIER, Thermal optimization of the building envelope in order to maximize its energy performance, Collection technique Cimbéton, p. 8, 2001.

[4] F. Ávila, E. Puertas et R. Gallego, Characterization of the mechanical and physical properties of unstabilized rammed earth: A review, Construction and Building Materials, 2020.

[5] A. Boursas et Z. Mehri, Study of the impact of building compactness on the energy performance of a residential 
building, Ghardaïa, 2012.

[6] D. Khawla, I. Dada et A. Bassoud, Thermal and mechanical characteristics of local materials, 01 Juin 2016.

[7] M. A. Lacasse, Sustainability and performance of building envelopes, NRC Publications Archive (NPArC), p. 8, Octobre 2003.

[8] N. Sotehi, Thermal Characteristics of Building Walls and Improvement of Insulation, Mentori-Constantine, 2010

[9] J. Borderon, R. Cantin et J. Virgone, Study of the dynamic thermal behavior of the uninsulated building envelope: a case of inert walls, Chez Conférence IBPSA France, Lyon, 2008.

[10] F. Joussellin, X. Faure, K. Johannes, P. Pierson et D. Quénard, Enveloppe hybride pour bâtiment économe, 2008

[11] Règles de l'Art Grenelle Environnement 2012, Professional recommendations: Double walls with thermal insulation from the outside, 2014.

[12] National Institute of Statistics and Demography (INSD), Annual Survey of Household Living Conditions (EA/QUIBB), 2005.

[13] A. Compaore, B. Ouedraogo, H. Guengane, E. Malbila, D. Bathiebo, Role of Local Building Materials on the Energy Behaviour of Habitats in Ouagadougou, IRA-International Journal of Applied Sciences, 8(2), pp. 63-72, 2017.

[14] X. Faure, Hybrid envelope for high energy performance building, 2007.

[15] J. Huet, J. C. Castel, D. Amoros et M. Laquerbe, On the determination of thermal diffusivity and thermal conductivity of homogeneous building materials in transient regime, Materials and construction, vol. 12(72), pp. 467-474, 1979 .

\section{Highlight}

The survey of public preference of local materials over modern materials was conducted and the preference of the public was highlighted. The specific thermal performance of CEB, cement block, double wall (cement block+CEB+air gap) was characterized. This study can serve as a theoretical basis for the choice of building materials.

\section{Nomenclature}

$\begin{array}{ll}\boldsymbol{\lambda} & \text { Thermal conductivity in } \mathrm{W} / \mathrm{m} \cdot \mathrm{K} \\ \mathbf{a} & \left.\text { Thermal diffusivity in } \mathrm{m}^{2} / \mathrm{s}\right) \\ \boldsymbol{\rho} & \text { Density in } \mathrm{kg} / \mathrm{m} 3 \\ \boldsymbol{C}_{\boldsymbol{p}} & \text { Spécific heat }(\mathrm{kJ} / \mathrm{kg} . \mathrm{K}) \\ \mathbf{K} & \text { Kelvin degree } \\ { }^{\circ} \mathbf{C} & \text { Celsius degree } \\ \boldsymbol{R T} & \text { Thermal resistance en } \mathrm{m}^{2} . \mathrm{K} / \mathrm{W} ; \\ \boldsymbol{e} & \text { Matériau thicknessin } \mathrm{m} \\ \mathbf{U p} & \text { Heat lost W/ }\left(\mathrm{m}^{2} . \mathrm{K}\right) \\ \boldsymbol{\varphi} & \text { Heat flow (in W/m }) \\ \mathbf{U g} & \text { Glazing thermal transmittance (in W/ }\left(\mathrm{m}^{2} . \mathrm{K}\right) \\ \boldsymbol{\Delta T} & \text { Température variation in Kelvin ; } \\ \boldsymbol{d}_{\boldsymbol{j}} & \text { Material layer or glass thickness }(\text { except air or gas), in } \mathrm{m} ; \\ \boldsymbol{E p} . & \text { Thickness } \\ \boldsymbol{R}_{\boldsymbol{s}, \boldsymbol{k}} & \text { Air gap or gas thermal résistance, in } \mathrm{m}^{2} . \mathrm{K} / \mathrm{W} \\ \boldsymbol{R}_{\boldsymbol{s} i} & \text { Wall internal surface thermal Resistance, in } \mathrm{m}^{2} . \mathrm{K} / \mathrm{W} \\ \boldsymbol{R}_{\boldsymbol{s} \boldsymbol{e}} & \text { Wall internal surface thermal Resistance, in } \mathrm{m}^{2} . \mathrm{K} / \mathrm{W}\end{array}$


$\boldsymbol{B A}$ Concrete

$\boldsymbol{C E B}$ Compressed Earth Block

$\boldsymbol{B L T}$ Cut lateriticblocks

INSD National Institute of Statistics and Development

$\boldsymbol{R T}$ Thermal Standards

TMV Vibrated Mortar Tile 